\title{
Telephonic Qualitative Research Interviews, when to consider them and how to do them
}

\author{
Muhammad Bilal Farooq \\ Auckland University of Technology \\ muhammad.farooq@aut.ac.nz \\ Charl de Villiers \\ The University of Auckland, and University of Pretoria \\ charl.devilliers@auckland.ac.nz
}

\section{Please cite as:}

Farooq, M.B. \& De Villiers, C. 2017. Telephonic Qualitative Research Interviews, when to consider them and how to do them, Meditari Accountancy Research, 25(2), 291 - 316.

\begin{abstract}
Purpose: The aims of this study are to: (1) review the literature examining the arguments for and against the telephonic qualitative research interview, (2) to develop criteria for assessing when the use of the telephone is suitable in qualitative research, and if suitable (3) to offer detailed strategies for the effective use of this data collection instrument.
\end{abstract}

Design/methodology/approach: The study is a thematic analysis of the literature, informed by the authors' experiences using the telephone, computer-based audio, and face-to-face interviews for an accounting research project involving 50 semi-structured interviews with managers.

Findings: The study identifies five criteria to determine the suitability of using the telephone in qualitative research interviews. In addition, the study offers a set of detailed strategies on what to do before, during and after a telephonic qualitative research interview.

Research implications: The study can assist qualitative researchers in deciding when to use the telephone and how to use it effectively.

Originality/value: The study builds on the limited prior research and provides a more complete list of strategies on the effective use of the telephone in qualitative social sciences research. These strategies are a synthesis of existing studies and observations drawn from the authors' study, which examines the work of organisational managers. In comparison, prior studies have been based on research projects that explored sensitive personal issues and emotive experiences not always related to managerial work.

Key words: research interviews; qualitative interviews; telephonic interviews, telephone interviews; computer-based audio; video conferencing; Skype 


\section{Introduction}

Qualitative interviews are traditionally conducted on a face-to-face basis (Novick, 2008; Qu and Dumay, 2011). This 'natural encounter' is often seen as necessary for the interviewer to build and maintain rapport with interviewees to enable the gathering of rich in-depth data (Gillham, 2005; Hermanowicz, 2002; Shuy, 2003). During face-to-face interviews, interviewees' body language and cues from the physical environment can also add to researchers' understanding (Bryman, 2001; Gillham, 2005). Traditionalists criticise this lack of contextual information and argue that the telephone is an inferior data collection instrument not suitable for qualitative research (Gillham, 2005; Hermanowicz, 2002). However, this argument has hardly been subjected to rigorous academic investigation (Holt, 2010; Glogowska, Young, and Lockyer 2011; Sturges and Hanrahan, 2004). In a review of the literature from 1988 to 2007, Novick (2008) found only 8 articles dealing specifically with the use of the telephone in qualitative interviews. Novick (2008) concludes that the lack of scholarly work in the field points to an unsubstantiated bias against the use of the telephone in qualitative research. In fact, qualitative researchers who have used the telephone, or compared telephonic and face-to-face interviews, do not find evidence to support the views of traditionalists (Irvine, Drew, and Sainsbury, 2012; Stephens, 2007; Vogl, 2013).

While prior studies offer valuable insights into the use of the telephone in qualitative interviewing, they have certain limitations. In some cases, the number of telephone interviews were small (Stephens, 2007; Opdenakker, 2006), and in most cases, the interviewees were not representative of the kind of interviewees typically targeted by managerial qualitative researchers, namely organisational managers. In other instances, the interviewees were university professors (Stephens, 2007), researchers (Tucker and Parker, 2014), or children (Vogl, 2013). In addition, much of the prior research using telephonic qualitative interviews focuses on the emotional and personal life of interviewees, e.g., the experiences of individuals visiting family members in jail (Sturges and Hanrahan, 2004), students' reasons for dropping out of college/university (Glogowska et al., 2011), mental health and employment, abuse and violence, parenting children with alleged criminal offences, experience of purchasing over-the-counter drugs and medicines from pharmacies, mental health following surgery (Irvine et al., 2012; Trier-Bieniek, 2012; Holt, 2010; Chapple, 1999; Carr and Worth, 2001), or the emotive experiences of employees within their initial 12 months of employment (Cachia and Millward, 2011). None of these studies involve interviews with employees and managers focused on the way they perform their work, which is typical of research in accounting and management. Finally, the study by Tucker and Parker (2014) provide the views of 24 highly experienced qualitative researchers, however only two of these researchers had any experience with telephonic qualitative research interviews.

This study overcomes the identified limitations by undertaking a thematic literature review informed by the authors' observations from a research project where interview participants are managers and the area of interest is their work done as managers. These interviewees relied heavily on the telephone as part of their daily work and were thus experienced and comfortable with the telephone. The project involved 43 telephone, 1 computer-based audio, and 6 face-to-face interviews. These observations, synthesised with the prior research, are used to: (1) review the literature examining the arguments for and against the telephonic qualitative research interview, (2) develop criteria for assessing when the use of 
the telephone is suitable in qualitative research, and if suitable (3) offer detailed strategies for the effective use of this data collection instrument.

Our findings build on the limited prior research examining telephonic qualitative research interviews. The study is the first to develop guidance specific to telephonic qualitative research interviews in which the research participants are managers and the focus of the research is the managers' work. In comparison, prior literature has focused on different interviewee groups and examined personal/emotive issues.

The remainder of this paper consists of a literature review, the research method, analysis and findings, and summary and conclusion. The literature review examines the primary criticisms levelled against the telephone, as well as the counter arguments. The findings section provides criteria for evaluating when to use the telephone and then offers a set of comprehensive strategies to follow before, during, and after the interview to ensure effective use.

\section{$2 \quad$ Literature review}

\subsection{Creating and maintaining rapport}

Traditionalists argue that the lack of visual cues affects the interviewer's ability to build and maintain rapport during the course of the interview (Shuy, 2003). Rapport is considered to be a key ingredient to creating a comfortable environment which encourages interviewees to speak openly and freely. This results in the interviewee sharing rich and in-depth data during the interview (Fontana and Frey, 2005). Furthermore, a face-to-face interview allows the researcher to meet the interviewee in person. This provides an opportunity to conduct rapport building exercises prior to the commencement of the interview. These include engaging interviewees in small talk, jokes and politeness routines (Shuy, 2003). The researcher can also offer friendship gestures such as a cup of coffee or a sandwich (Chapple, 1999). These acts help to break the ice and create a friendly environment conducive to a free flowing conversation. In comparison, telephonic interviews make it harder to achieve these goals/advantages, resulting in lower levels of rapport, and affecting the quantity and quality of data collected (Sweet, 2002).

\subsubsection{Findings of empirical studies}

In a study aimed at understanding the experiences of individuals visiting family members in jail, Sturges and Hanrahan (2004) compared data acquired through 21 face-to-face qualitative interviews with 22 telephonic qualitative ones. The study found no difference in the number, the nature, or the depth of responses. They conclude that the telephone and face-to-face interviews provide data of comparable quantity and quality.

Vogl (2013) compares 56 face-to-face with 56 telephone interviews. The study found that there was no significant difference in the duration of the conversation, the total number of words spoken, the proportion of words spoken by interviewees, the number of responses, the number of pauses, or the need for clarification using the two modes of communication. The study concludes that there was no difference in the motivation and level of rapport achieved. Instead, Vogl (2013) attributes differences in responses to sensitive questions to the personality of the interviewee. Similar observations have been cited by Stephens (2007), Holt (2010), Glogowska et al. (2011), Trier-Bieniek (2012) and Chapple (1999) who have used 
the telephonic qualitative research interview. Additionally, Deakin and Wakefield (2014) share their experience of conducting computer-based video conferencing (using Skype) and face-to-face interviews. They argue that they faced no difficulty building rapport with their study participants and that the level of rapport achieved was comparable to their face-toface interviews.

\subsubsection{Counter arguments in favour of using the telephone}

It is argued that the telephone interviews provide a more balanced distribution of power between interview participants (Vogl, 2013). This potentially encourages interviewees to speak freely, and may give greater control to the interviewee to direct the conversation towards areas they perceive as important. Furthermore, while the interviewer may over time develop the ability to avoid biases and stereotyping of interviewees based on visual traits and behaviour, the same cannot be said of the interviewee (Vogl, 2013). Indeed, the interviewee has no personal commitment in the research and may very well be biased by the appearance and behaviour of the interviewer. Thus, by removing these visual distractions the use of the telephone can reduce some of these biases. There is also a risk that with face-to-face interviews, too much rapport could lead to the discussion drifting and losing its focus. Interviewers are encouraged to maintain a certain degree of distance and formality with research participants (Tucker and Parker, 2014). Thus, the role of rapport within the interview should be understood in context.

Finally, researchers have found that when interviewees were given the option, many chose the telephone instead of a face-to-face interview and were appreciative of being given the choice (Holt, 2010; Sturges and Hanrahan, 2004). Reasons for this preference was that with the telephone, interviewees perceive a greater level of anonymity and privacy than with face-to-face encounters (Carr and Worth, 2001; Holt, 2010; Sturges and Hanrahan, 2004). The possibility of losing face is reduced and interviewees are more comfortable openly discussing personal opinions (Chapple, 1999; Opdenakker, 2006; Sturges and Hanrahan, 2004). Additionally, many shy interviewees are not comfortable with face-to-face interactions (Tucker and Parker, 2014). For them, a telephone interview can assist by decreasing social pressure, whilst building rapport (Vogl, 2013).

\section{$2.2 \quad$ Impact on the communication process}

Traditionalists argue that facial expressions and body language are an integral part of the communication process (Gillham, 2005; Kvale and Brinkmann, 2008; Rowley, 2012). These visual cues are potentially lost during a telephone encounter. This is argued to create four challenges for researchers.

First, the lack of visual cues creates a risk of misunderstandings which may ultimately lead to a breakdown in the communication process (Hermanowicz, 2002). Second, the researcher loses key non-verbal visual data (Novick, 2008). Traditionalists argue that this additional detail gives richness to the data collected which is missing in telephone interviews (Opdenakker, 2006). Third, the researcher is unable to use body language as a natural tool for probing and seeking clarifications or elaborations to answers given (Stephens, 2007). Fourth, interviewers cannot rely on visual cues to assess the interviewee's level of interest. Visual cues inform the researcher when there is a need to motivate and stimulate the interest of interviewees (Irvine et al., 2012). As a result, telephone interviews require greater concentration and energy to ensure that the interviewee is engaged and there is a 
natural flow in the conversation (Shuy, 2003). Otherwise the interview is likely to be of shorter duration, with less data collected.

\subsubsection{Findings of empirical studies}

The growing reliance on the telephone (and internet) for communication is well documented (Carr and Worth, 2001; Cachia and Millward, 2011), with more and more people communicating by telephone and on the internet (Trier-Bieniek, 2012). A ringing telephone is almost always picked up and there are rarely long periods of silence during telephone conversations (Frey, 1983). The ability to build rapport and achieve a flowing conversation is evidence that people are confident and comfortable using the telephone for communication purposes (Holt, 2010; Sturges and Hanrahan, 2004; Trier-Bieniek, 2012).

Children's confidence with the telephone grows with age, with the quantity and quality of data obtained from older children being higher (Vogl, 2013). Similarly, Tucker and Parker (2014), find that researchers often avoid telephone and computer-based audio and video conferencing technologies (such as Skype) for interviewing simply because they are unfamiliar with the technology. These researchers accept that if they used this technology more frequently they may develop a familiarity and comfort with the technology.

Furthermore, studies find no significant increase in the need for clarification during telephone interviews (Irvine et al., 2012). Thus, the lack of visual cues did not result in a breakdown in the conversation or misunderstandings, as argued by traditionalists. In any event, difficulties encountered can be overcome by relatively simple means and are discussed in section 4.2.14 (Sturges and Hanrahan, 2004).

\subsubsection{Counter arguments in favour of using the telephone}

It is argued that the qualitative telephonic interview is not being recommended for all participant groups. Instead, researchers need to carefully consider their target research participants when selecting their interview mode. For example, when interviewing younger age groups, that are more dependent on communicating using technologies, a more effective interviewing tool would be to use the telephone and computer-based technologies such as Skype, MSN Messenger, Facebook, etc. (Opdenakker, 2006). In comparison, the telephone and computer-based technologies may not be suitable for interviewing older age groups (Chapple, 1999).

In additionally, the lack of visual cues forces both interviewer and interviewee to listen carefully (Trier-Bieniek, 2012). Effective listening is a key ingredient for successful interviewing (Qu and Dumay, 2011). Clearly articulating questions is another pre-requisite for a good interview (Hermanowicz, 2002). Again, the lack of visual cues forces both the interviewer and interviewee to articulate clearly the messages they wish to communicate (Stephens, 2007). Effective listening and clearly articulating a message improves the quality of the communication process resulting in fewer misunderstandings. Thus, the telephonic interview can provide rich data, an important consideration for qualitative studies (Sturges and Hanrahan, 2004). Therefore, the lack of visual cues offers certain advantages.

Proponents of telephonic qualitative interviews also note that that interpreting or attempting to interpret body language can be a difficult and challenging task that is best left to psychologists (Chapple, 1999; Novick, 2008). The argument that interviewees are incapable of articulating their message adequately or that they may try to mislead the 
interviewer may not always hold true. For example, these assumptions are less likely to apply when interviewees are managers who are describing their work than where individuals, are asked to relate their feelings.

Finally, during qualitative interviews researchers will often identify new subquestions/probes (Hermanowicz, 2002). Here the lack of visual contact allows the interviewer to unobtrusively notate follow-up questions whilst the interviewee is speaking. Like effective listening, note taking is another important feature of successful qualitative interviews (Qu and Dumay, 2011).

\subsection{Accessing the participant's natural environment}

Traditionalists argue that face-to-face interviews allow the researcher to visually access the participant's natural environment (Gillham, 2005; Miles et al., 2014; Shuy, 2003). This allows the researcher to collect key contextual data necessary for qualitative research, such as field notes (Bryman, 2001). In comparison, telephone interviews suffer from a lack of visual access which prevents the researcher from collecting key contextual data. In addition, the interviewer is unable to assess whether the interviewee is comfortable in their environment and thus unable to ensure a good interview ambience (Opdenakker, 2006). Finally, because the interviewer is not aware of elements that may create distractions in the interviewee's environment, the interviewer is not able to take remedial action. (Glogowska et al., 2011).

\subsubsection{Findings of empirical studies}

These arguments of traditionalists find their roots in ethnographic studies which require researchers to build a good understanding of the participant's natural environment (Sturges and Hanrahan, 2004). There is arguably a lesser need for contextual data in nonethnographic studies. Thus the selection of a particular interview mode is dependent on the objectives of the research (Tucker and Parker, 2014). For example, when investigating how a manager undertakes a particular task, a researcher will have to decide whether contextual data is required and if this can be collected separately from the interview itself i.e. using observation.

\subsubsection{Counter arguments in favour of using the telephone}

Interviewees tend to be busy (Holt, 2010) and busy participants are often more willing to agree to a telephone interview, because it is easier to cancel and reschedule (Cachia and Millward, 2011; Chapple, 1999). The interviewee generally feels less embarrassed to reschedule, given the fact that the interviewer has not incurred travel/accommodation time and cost. Deakin and Wakefield (2014) report that some interviewees stated they did not have enough time to undertake a face-to-face interview, but were willing to participate using computer-based video conferencing.

Face-to-face interviewing of participants in their own environment is said to enable the collection of contextual data. However, there could be certain challenges associated with doing so. For example, Sturges and Hanrahan (2004) observed that interviewing participants in a noisy and distractive environment (i.e. a prisoner's visitor room in a jail) was not ideal, and that participants did not want to be interviewed in the presence of individuals (i.e. prison guards) they feared may retaliate against them. These challenges can be avoided by conducting a telephone interview. Keeping both parties in their respective locations, the telephonic interview also requires less space (Sweet, 2002). This consideration applies particularly when interviewing individuals working in small, shared office spaces (e.g. when 
interviewing managers in small organisations that do not have the luxury of private conference rooms). With both parties on their own turf, both the interviewer and interviewee are more likely to be more relaxed and comfortable during the interview.

Perhaps the most commonly cited advantage of using the telephone is the reduction in both time and cost to researchers (Sturges and Hanrahan, 2004; Stephens, 2007), and allows for a larger number of interviews on a smaller budget over a shorter period of time (Trier-Bieniek, 2012). With the increasingly globalised nature of accounting research, research designs often call for interviews with participants in dispersed locations in order to gain diverse perspectives (Tucker and Parker, 2014). One academic states that s/he would rather interview by telephone than not at all (Tucker and Parker, 2014). Telephonic interviews also allow the researcher to gain access to individuals based in locations which may be closed to the researcher e.g. religious sites, communities, cults, and military bases (Opdenakker, 2006). Some of these locations are dangerous to visit in person and to telephone is a safer option (Sturges and Hanrahan, 2004). In addition, the telephone allows researchers who are physically disabled or caring for children to undertake a study that may otherwise present challenges (Glogowska et al., 2011).

Table 1 provides a summary of the criticisms of traditionalists and the counter arguments of proponents of the telephone interview.

Table 1: Arguments and counter arguments around qualitative interviewing by telephone

\begin{tabular}{|c|c|c|}
\hline & THE TELEPHONE IMPACTS & $\begin{array}{c}\text { COUNTER ARGUMENTS OF PROPONENTS OF QUALITATIVE } \\
\text { TELELPHONE INTERVIEWS }\end{array}$ \\
\hline \multirow[t]{5}{*}{1} & \multirow{5}{*}{$\begin{array}{l}\text { Ability to create and maintain } \\
\text { rapport }\end{array}$} & Empirical evidence does not support this assertion \\
\hline & & Improved power balance \\
\hline & & Reduces interviewer bias \\
\hline & & Avoids having too much rapport \\
\hline & & Promotes a participant-centred approach \\
\hline \multirow[t]{5}{*}{2} & \multirow[t]{5}{*}{ The communication process } & $\begin{array}{l}\text { Changing communication norms favouring telephone } \\
\text { communication }\end{array}$ \\
\hline & & $\begin{array}{l}\text { May offer a more suitable interview mode should participants } \\
\text { comprise younger age groups who prefer this mode of } \\
\text { communication }\end{array}$ \\
\hline & & Encourages careful listening and clear articulation of speech \\
\hline & & Avoids the tricky business of interpreting body language \\
\hline & & Allows note taking without distracting \\
\hline \multirow{5}{*}{3} & \multirow{5}{*}{$\begin{array}{l}\text { Visual access to the interviewees } \\
\text { natural environment }\end{array}$} & Not every qualitative study requires contextual data \\
\hline & & Avoids environment noise and distractions \\
\hline & & Telephone interviews require less space \\
\hline & & Time and cost is lower \\
\hline & & $\begin{array}{l}\text { Interviews are easier to reschedule and therefore potential } \\
\text { interviewees are more willing to agree to participate in the } \\
\text { research }\end{array}$ \\
\hline
\end{tabular}

\section{Research method}

The study is a thematic literature review informed by the authors' experience of conducting semi-structured telephone, computer-based audio and face-to-face interviews. These interviews were conducted as part of an accounting research project aimed at understanding how sustainability reports are prepared and assured in the Australia and New 
Zealand context. A total of 50 interviews were conducted, of which 43 were by telephone, 1 was a computer-based audio call (using Skype software), and 6 were face-to-face. The interviews took place between February and August 2014 and lasted an average of 63 minutes.

The interviews were semi-structured and a conversation style was adopted (Kvale and Brinkmann, 2008; Rowley, 2012). Interview participants comprised of 35 managers responsible for preparing non-financial disclosures in organisations based in Australia and New Zealand. These organizations comprised a diverse mix of large multinationals and smaller local operators, private and public entities, listed and non-listed enterprises. The remaining 15 interviewees comprised of assurance practitioners based in Australia and New Zealand and engaged by reporters to provide assurance over their non-financial disclosures.

Interviews were recorded, transcribed and then analysed. Follow up questions were emailed to the participants. A summary of the analysis was sent back to participants for review and feedback. Research participants also sent through internal organisational documents that would offered additional insights relating to the sustainability reporting and sustainability assurance process. These documents provided an additional layer of data that helped build an understanding of the phenomena under investigation.

Observations from the authors' study were synthesised with the extant literature on telephonic qualitative interviews, to develop a more comprehensive set of strategies for success with telephonic qualitative interviews. These strategies are focussed on providing key insights on interviewing organisational managers on matters relating to their work, as opposed to the prior literature, which was focussed on interviewing individuals to understand personally sensitive and emotive experiences. These strategies are organized into the three stages of before, during, and after the interview.

\section{$4 \quad$ Analysis and findings}

This section consists of 4.1, a set of criteria for evaluating the suitability of using the telephone in qualitative interviews, and 4.2, a comprehensive set of strategies for researchers to follow to ensure successful telephonic qualitative research interviews.

\subsection{Criteria for assessing the suitability of telephonic qualitative research interviews}

While the telephone offers a useful substitute to face-to-face interviews, researchers should justify why they have chosen this mode of interviewing (Glogowska, et al., 2011). The authors' study identifies five questions researchers should consider to assess the suitability of using the telephone in qualitative research.

\subsubsection{Do you need contextual data?}

Telephonic (or computer-based) qualitative interviews do not provide researchers with contextual data (Chapple, 1999). Researchers will need to examine the unique requirements of their study and will need to assess if collecting contextual data is a critical requirement for achieving their research objectives. However, collecting contextual data (through observations) and collecting experiential data (through interviews) represents two different data collection instruments (Bryman, 2012 ). It is also possible for researchers to use both instruments in the same study. For example, Sturges and Hanrahan (2004) in their study, 
conducted site visits to collect contextual data and conducted telephonic interviews to collect experiential data. Researchers should consider the requirements of their study and the unique circumstances that they face when tailoring a data collection strategy.

For example, in the study conducted by the authors, the aim was to understand how managers prepared sustainability reports and how sustainability assurance providers undertook assurance of these documents. The objectives of the study did not necessitate collecting contextual data on where the participants lived, the condition of their offices, or how the participants dressed. A review of the extant literature revealed that such things are rarely, if ever, discussed in qualitative studies on sustainability reporting and sustainability assurance. Contextual data in sustainability reporting and assurance literature comprises mostly of background information on institutional pressures (including political and regulatory, social, and economic). This is collected by reading reports (issued by regulatory agencies and bodies), reviewing academic papers, and most importantly by asking research participants what is going on, what pressures they face, and what key influencers affect their work.

Furthermore, the study undertaken was not a case study in which a researcher relies on multiple data sources including observing on how managers go about their work or how they interact with each other. Rather the aim was to interview managers working in a diverse range of organisations facing different challenges and approaching their work in different ways. This is not to say that case studies or ethnographic research serves no purpose or holds no value. Far from it: such types of research serve to enrich our understanding of the complex world in which we live in. However, the point of emphasis here is that tools should be selected that are appropriate for the particular research projects. Additionally, in the authors' study, it was found that interviewing a manager in a visitor room, conference room, or a cafe provides no more or less contextual data than interviewing the same manager over the telephone (or using computer-based technologies). In fact, it is found that a manager was more likely to take the interview in his/her own office if conducted over the telephone (or using computer-based technologies) than if conducted on a face-to-face basis where the interview is more likely to be conducted in a visitor or conference room. Thus, the telephone interview allows the manager to access documents and other resources $\mathrm{s} /$ he has in her/his office during the interview (discussed in 4.2 below). Similarly, there is very little contextual data to be collected from a one-hour interview in an organisations conference room.

\subsubsection{Is your target population experienced in using the telephone?}

Researchers should assess the target interviewee's experience and confidence with the telephone (or computer-based technologies) for conversations of a long duration (Holt, 2010; Trier-Bieniek, 2012). For example, a 2014 survey shows that people with access to a landline telephone was estimated at $8 \%$ in India, $26 \%$ in China, $37 \%$ in Brazil, Russia $43 \%$ and $60 \%$ in US (Pew Research Centre, 2015). The same study shows that $14 \%$ of people in India owned a smart phone, $67 \%$ owned a mobile phone but not a smart phone and $19 \%$ owned no mobile phone. These figures are $55 \%, 42 \%$ and $3 \%$ in China; $24 \%, 63 \%$ and $13 \%$ in Brazil; $33 \%, 63 \%$ and $13 \%$ in Russia; and $58 \%, 32 \%$ and $10 \%$ in US respectively. Thus while ownership of a mobile phone is higher than landline ownership, the number of people with a smart phone remains lower (Pew Research Centre, 2015). 
Similarly, access to the internet varies considerably across the world. For example, in 2014 adults who had access to the internet (through computer or smart phone) was estimated at $20 \%$ in India, $63 \%$ in China, $51 \%$ in Brazil, $73 \%$ in Russia and $87 \%$ in the US have access to the internet (Pew Research Centre, 2015). The same study indicates that internet usage is more common in younger, higher educated, English speaking adults.

Researchers need to also consider whether any language barriers exist between interview participants (Chapple, 1999). Both the interviewer and interviewee should be fluent in the language used to communicate during the interview process.

Two observations from the authors' study are relevant here. First, the managers interviewed were experienced in using the telephone (and to a lesser extent computerbased technologies) as part of their day-to-day work, relying on the telephone to communicate with colleagues and business partners based in geographically dispersed locations. This meant that they were experienced and comfortable using the telephone to communicate with people they had not met in person and who belonged to different nationalities, cultures, and with varying English language skills. However, this may not be the case with all managers and researchers will need to evaluate their target participant group carefully before selecting their interview mode.

Second, although the authors were not originally from Australia or New Zealand, they were educated in English and their English was fluent. Thus, the interviewers' background did not affect their ability to build rapport or to communicate effectively. Two interviewees were not native English speakers, but both were fluent in English (having worked in Australia for quite some time) and the differences in background did not affect the communication process or the ability to build rapport. Again it should be emphasised that both the interviewer and interviewee need to be fluent (both speaking and listening) in the language of communication. If this is not the case, then the telephone would not be a suitable mode of interview.

\subsubsection{What is your own experience with the telephone?}

Researchers should consider their own experience with the telephone (and computer-based communication technologies) for long conversations (Sturges and Hanrahan, 2004); discussing personally sensitive issues with family and friends; and/or discussing work related issues with colleagues and research team members. This would demonstrate that they have developed the skills and confidence necessary to undertake telephonic (or computer-based) qualitative research interviews. A lack of experience is also one of the reasons why many researchers are reluctant in using technology in qualitative research (Tucker and Parker, 2014).

Researchers with little or no experience with the telephone (or computer-based technologies) may want to practice with a team member or colleague before conducting their first interview. However, as Hermanowicz (2002) points out, interviewing like any other activity requires practice to perfect. Similarly, we would recommend that after a few practice sessions the researcher should start to conduct actual telephonic (or computerbased technologies) qualitative research interviews. Over time, the researcher will grow in confidence and improve their telephonic interviewing skills. If these criteria are met the researcher may consider using the telephone as a qualitative data collection instrument. 


\subsubsection{Should you use the telephone or computer-based technologies?}

Researchers will also have to consider whether it is more suitable to use the telephone or alternatively computer-based communication technologies for their research. In our study, participants were initially offered the option of either a telephone or a computer-based interview using Skype. The majority of participants, however preferred the telephone over Skype. The low preference for computer-based interviews can be explained by five possible reasons.

First, many participants provided their mobile telephone numbers on which to be contacted for the purpose of the interview. This may be due to the interviewee's uncertainty regarding their physical locality on the date and time of the interview. Alternatively, many interviews were taken in the privacy of the conference or visitor room. Some of these rooms did not have a telephone line available and the manager simply used their mobile phone.

Second, while everyone has a mobile phone not everyone has a smart phone which is necessary for Skype calls (Deakin and Wakefield, 2014; Seitz, 2015). Additionally, not everyone has access to the internet on their smart phones. Those that do may not have sufficient data credit to support the call or may not wish to use their data for the interview.

Third, Deakin and Wakefield (2014) suggest that both interviewer and interviewee should be willing to undertake some pre-interview hardware and software checks to ensure that a smooth Skype call is possible. Busy managers generally eschew such steps.

Fourth, the majority of participants scheduled to have the interview while at work. The interview was often taken in a conference or visitor room. These rooms were preferred over taking the interview (via Skype or telephone) in their office/cubicle as "it's a bit more private here". Some of these rooms had teleconferencing facilities (but no provision for video conferencing), which managers used for the interview.

Fifth, not all office computers have software such as Skype installed for managers to use. Organisations will often have policies against the downloading of software onto office computers without the permission of the IT department. Managers may not wish to take the time and effort to secure approval to download and install Skype on their computer.

After the first (and only) computer-based interview (using Skype) the authors decided not to offer the Skype option to new recruits. This was because the one computer-based interview was an audio call as the participant preferred not to use Skype "video call" option and the interviewer felt it inappropriate to request the manager to do so. If the video option is not selected, or if during the interview the video is turned off or if the image is blurred or frozen due to a drop in the internet speed, then this interview mode effectively becomes a telephone call of a lower quality (Tucker and Parker, 2014). Additionally, the experience of this one computer-based "audio" interview was not encouraging. Despite both the interviewer and interviewee being located in developed countries (New Zealand and Australia) with access to reliable internet connections, the quality of the call/internet connection fluctuated during the interview. Although this did not cause a disconnection or impact the communication process the interviewer concluded that given the unreliable nature of this communication tool, this interview mode should not be used. 
It is anticipated that these limiting factors will be less prevalent in the future. If this is the case and interviewees indicate their willingness to use computer-based technologies, there should be fewer problems. Under these conditions, invitations should clearly state that the interview will be by computer-based audio or video and the type of software which will be used for this purpose. If participants are uncomfortable with this option, the telephone may be an appropriate alternative.

Affordable telephone packages may exclude calls to mobile phones and using computerbased communication technologies such as Skype offer a more affordable alternative (Deakin and Wakefield, 2014). Skype software is downloadable free of charge and enjoys global recognition (Deakin and Wakefield, 2014). The software also allows calls to be made to landline telephone and mobile telephone numbers (albeit at a cost) and with the option of video conferencing provides as an added advantage over the telephone (Tucker and Parker, 2014). Finally, the affordability of internet data could under some conditions be an issue, but will probably reduce in importance over time.

\subsubsection{What is the budget of the research project?}

As discussed in section 2.3.2 one of the benefits of undertaking telephone (and computerbased) interviews is the lowering of time and cost (Sturges and Hanrahan, 2004; Stephens, 2007) coupled with the ability to cover a larger number of interviews on a smaller budget in a shorter timeframe (Trier-Bieniek, 2012). This was a key factor that motivated the authors to use the telephone and computer-based technologies for their study. Interview participants were based in dispersed locations across Australia and New Zealand and travelling to these locations on a limited budget and a short timeframe was simply not an option.

However, saving time and cost in itself is not be a valid justification for using the telephone (or computer-based technologies). Researchers should consider their project and research objectives (i.e. is contextual data required), the characteristics of their target population, as well as their own experience using the telephone and computer-based technologies in communication. In their study, the authors found that they did not require contextual data and since both the interviewer and interviewee were experienced and comfortable with these technologies, using the telephone and computer-based audio and video interview technologies was considered acceptable.

The following discussion focuses on the strategies researchers can use to ensure an effective telephonic qualitative interview. These strategies are based on a synthesis of prior literature and observations gained from the research project described in the method section. The source of the information will be made clear by way of either referencing the prior literature, or referring to the experience gained from the research project described in the method section.

\subsection{Strategies for successful qualitative telephonic interviews}

The following steps should be undertaken before conducting the interview:

\subsubsection{The interview guide}

Researchers need to develop a well thought out interview guide (Hermanowicz, 2002). This helps to build rapport with interviewees who feel comfortable opening up to the researcher (Braun and Clarke, 2013). Some researchers have recommended the interview guide be 
practiced or pre-tested using a telephone (or computer-based technologies) on a member of the research team or colleague (Burke and Miller, 2001; Glogowska, et al., 2011). Feedback received can be used to refine the questions, the sequencing of these questions and to assess the time required.

Others researchers have opted to test the interview guide on research participants. For example, after conducting five telephone interviews, Mealer and Jones (2014) reviewed and revised their interview guide. We adopted a similar approach in which the interview guide was reviewed and revised after two face-to-face interviews conducted prior to the telephone interviews.

\subsubsection{Recruiting participants}

Stephens (2007) used written invitations to recruit five university professors for his telephonic qualitative research interviews. Sturges and Hanrahan (2004) used their site visit to recruit participants in person. Trier-Bieniek (2012) used a website to recruit her telephone interviewees. Glogowska et al. (2011) sent telephone participants a letter invitation followed by a telephone call requesting participation. Mealer and Jones (2014) used the telephone to recruit their research participants. These examples demonstrate how a number of different approaches can be used (individually or in combination) to recruit telephone interviewees (Deakin and Wakefield, 2014). Researchers should tailor their approach according to the requirements of their research and the characteristics of their target interviewees.

We used a combination of accessing the researcher's network of contacts, cold calling, sending email invitations, and snowball sampling to recruit managers ${ }^{1}$. While cold calling may be inappropriate for studies examining personally sensitive topics (Glogowska, et al., 2011) this was not the case in the authors' study, which aimed to understand the work managers were undertaking. It was also found that telephone invitations provide a more effective approach to recruiting participants than the written invitations such as emails, letters or faxes a point also noted by earlier researchers (Stephens, 2007; Burke and Miller, 2001). However, cold calling/telephone invitations involve considerable effort as a number of calls have to be made before busy managers are willing to participate. Researchers need to be extremely organised and are encouraged to maintain a log of who was called and the result of that call.

\subsubsection{Pre-interview telephonic conversation}

Qualitative researchers are encouraged to have a telephonic conversation with their study participants prior to the actual interview (Hermanowicz, 2002). This can take place when contact is first made with the participant (i.e. at the recruitment stage). Alternatively participants who have been invited to participate via email (whether they have accepted or not) can be encouraged to further discuss the study over the telephone (Hermanowicz, 2002). The aims of the pre-interview telephonic conversation are threefold, addressing participant concerns, building rapport and creating interest, and explaining the interview style.

\footnotetext{
${ }^{1}$ An email invitation was used when a telephonic invitation was not possible. This would occur if the manager's telephone number was not available and the organizations head office reception desk or the manager's personal assistant requested an email invitation for initial review.
} 


\section{Address concerns}

The pre-interview telephonic conversation provides an opportunity for the researcher to "sell" the project. The researcher can immediately address any concerns and/or misunderstandings that the participant may have thus putting participants at ease (Irvine and Gaffikin, 2006). Issues of data confidentiality and participant anonymity have been observed as a cause of participant concern in previous studies (Chapple, 1999; Nassar, et al., 2011).

We identified lack of time, aims of the research, data confidentiality, and participant anonymity as the major concerns of manager interviewees. These were addressed in the following ways: First, the authors explained to managers how the purpose of the research was not to find fault with their organisations practices but rather to understand/learn how they undertake a particular process. Furthermore, they did not need to answer questions they were not comfortable answering. Second, all participants were emailed two documents, namely a participant information sheet (outlining the participant rights, including data confidentiality and anonymity), and a participant consent form, to comply with standard research procedures. Third, as the research progressed, the interviewer informed new participants of the number of previous interviews to increase the likelihood of participation. Being part of a larger pool of interviewees gave the participant more assurance of anonymity. Additionally, managers would feel they had more to gain by participating in the study and sharing their experiences and knowledge.

\section{Build rapport and create interest}

The pre-interview telephonic conversation allows researchers to converse with participants in a friendly yet professional manner (Glogowska, et al., 2011). The conversation also provides an opportunity to pique participants' interest in the research. This can be achieved in three ways.

First, the topic of research represented the managers' day-to-day work. It was something that they were engaged in and facing challenges with. Many of the managers felt passionately about the topic of investigation (Trier-Bieniek, 2012). The authors simply had to leverage this interest. The authors would inform participants how they were interested in learning about "what was going on", "what you guys are doing", "you're pioneers in the field" and "I want to get your experiences and perspectives".

Second, the authors attempted to leverage the participant's sense of altruism (Cachia and Millward, 2011; Irvine and Gaffikin, 2006). Managers were informed on how their contribution was important to research conducted and how this research would benefits others (Chapple, 1999; Glogowska, et al., 2011). In our study we told participants that "the academic community relies on the support of the business community to promote knowledge and learning". Consequently, at the conclusion of the interview participants often would ask and remark: "Was this helpful? Good! I'm glad I could help!" and "If you have any other questions feel free to flick me an email".

Finally, participants were informed that the findings of the research would be shared with them. Thus participation in the research and sharing their knowledge would be beneficial for them. Many managers expressed interest in reading the findings of the research "I look forward to reading your findings". 


\section{The interview style}

In this study, the authors' attempted to present the interview as an important but relaxed conversation (Hermanowicz, 2002) aimed at understanding the experiences and perspectives of the interviewees. The authors attempted to overcome any misconceptions or stereotypical views about interviews. The authors wished to distinguish, in a subtle and indirect manner, the research and the interview from both a boring and stressful laboratory experiment on the one hand and an intrusive newspaper or magazine interview on the other.

We recommend that researchers undertake this conversation before the interview itself, to ensure it remains discreet from the scheduled interview time. We observed that managers were busy and were keen to start the interview quickly. They often had meetings scheduled immediately after the interview. Additionally, the interview was often conducted in a conference or visitor room that was booked for a specific time slot. Of course, even with time constraints, the interviewer should always answer participants' questions before or during the interview.

\subsubsection{Email communication}

Participants contacted through email were provided with information on the aims of the research, data confidentiality and participant anonymity, estimated time required, and a broad outline of the questions that would be asked. Thus, the email was acting as a substitute for the pre-interview telephone conversation. The email was brief and carefully worded to convey positivity, professionalism, and friendliness.

Providing a broad overview of the aims of the research and a general outline of the questions allows participants to think about their answers and ultimately provides a richer set of data (Burke and Miller, 2001). Managers can review files and documents prior to the interview or at least ensure they have these documents at hand during the interview. The contact details of the authors were also provided. Interviewees could take comfort in the experience of the authors on the team.

Often the authors would exchange numerous emails with a participant prior to the interview. This also serves to build rapport with interviewees (as also noted by Deakin and Wakefield, 2014; Seitz, 2015). Consequently, researchers need to continuously monitor emails in order to provide a quick reply to interviewees who have questions regarding the research or who wish to reschedule the interview. The email correspondence should be kept suitably organized into folders to enable a review these emails during the analysis and write up stage of the research.

\subsubsection{Negotiating interview time}

Interview times vary, with some participants willing and able to allocate more time than others (Burke and Miller, 2001). Researchers need to negotiate the time allocated to the interview with managers. For examples, a manager communicated (via email) that she was scheduling 30 minutes for the interview. The interviewer replied "I was hoping for 1 hour but I can live with 45 minutes". The interviewee replied "let's go for 1 hour".

Another manager explained that while organisations allow their employees time to participate in academic research this would usually be limited 2 to 3 hours in a year. Furthermore, the interviewee remarked that they receive many requests to participate in 
academic research each year, therefore they had limited time for the interview. While a busy manager may be able to give 30 minutes to the interview "now", the same manager may be willing to allocate more than an hour in two months' time when their workload is more manageable. Thus, researchers need to be flexible when recruiting managers for interviews.

Another strategy used by the authors was to request reluctant participants to allocate " 30 minutes or so" for the interview. Interviewees generally enjoy explaining their work during an interview and these interviews eventually often lasted 45-60 minutes.

\subsubsection{Setting up the equipment}

Interviewers need to use a hands free telephone set (Trier-Bieniek, 2012). The call should be switched to speaker, allowing the interviewer to free his/her hands for note taking, sipping tea or water. As Stephens (2007) narrates holding the telephone while writing notes and reading presents both a challenge and a distraction.

The recording of the interview can be done using either a tape recorder or digital audio recorder, placed next to the telephone speaker (Cachia and Millward, 2011; Trier-Bieniek, 2012). Alternatively, a two-way device (or an in-line recorder) that connects to the telephone on one end and a tape recorder on the other can be used (Chapple, 1999; Stephens, 2007; Sturges and Hanrahan, 2004). Glogowska et al., (2011) states that this twoway device filters background noise. This is particularly useful during the transcription stage which can be particularly challenging with background noise.

Researchers need to ensure that they are familiar with the equipment and how to use it (Kazmer and Xie, 2008). The equipment may suffer from breakdown or malfunction (Kazmer and Xie, 2008) and therefore should be tested (Burke and Miller, 2001). Researchers need to be confident that their equipment will perform without any breakdowns or stoppages for the entire duration of the interview (Burke and Miller, 2001).

In our study, we used an audio digital recorder. The disadvantage of this device is that it does not filter out any background noise as the two-way device. The advantage however is that it is a pocket size device which connects directly to a personal computer or laptop. The authors could easily transfer audio files from the device onto a computer. The device used by the researcher came with a free easy to install (plug and play) software which allowed the audio files to be organized and replayed at various speeds thus facilitating transcription and analysis. A smart phone was used as a backup recording device.

\section{Computer-based communication technologies}

Computer-based audio and video communication can be undertaken using software such as Skype. The researcher would require a computer (or a smart phone) and an internet connection (Seitz, 2015). The latest version of the Skype software should be installed at both ends (Seitz, 2015). The hardware should be tested (e.g. the webcam should be working) and the computer/smart phone fully charged (Hanna, 2012).

The Skype website also provides information on internet speeds that are required. A slow internet connection from either side (interviewer or interviewee) will affect the quality of the Skype call resulting in the call dropping i.e. loss of connection, requiring call back, temporary disconnection resulting in freezing of video images and lags or delays in the 
receiving and sending of audio and video images (Deakin and Wakefield, 2014; Seitz, 2015; Tucker and Parker, 2014). Such technical difficulties disrupt the natural flow of the interview.

Skype calls consume data and both the interviewer and interviewee need to ensure that they have sufficient data to support the Skype call. This requires assessing how long the Skype interview is expected to last and whether it will be a Skype audio only or Skype video call/interview which requires more data. An estimate can be made by using the information provided on the Skype website. The researcher should consider if the interviewee is comfortable using their own data for the purpose of the research.

Furthermore, from the authors' personal experience, a computer usually provides a more reliable and better quality Skype call (audio and video) than a smart phone. Computers' larger screens make it easier to pick up visual cues, such as facial expressions and body language.

\subsubsection{The interview location and environment}

Researchers should ensure that they are comfortable, the room is quiet and there is no risk of interruption (Chapple, 1999). Interviewers should start by asking interviewees if they are comfortable and ready to proceed with the interview or if they would like to reschedule (Stephens, 2007). Privacy is important at both ends, especially when sensitive or confidential matters are covered (Mealer and Jones, 2014). Environmental noise impacts both the interview conversation and the subsequent transcription (Kazmer and Xie, 2008). Therefore, interviews should preferably be conducted in an office type environment (Seitz, 2015).

The drawback with using the telephone (or computer-based technologies) is that participants may decide to take the interview using their mobile phone (or smart phone) during office hours, lunch breaks, at home, while their children are napping, in the car or while on the bus/train commuting home from work (Trier-Bieniek, 2012). Consequently, interviews may suffer from mobile phones losing signal while interviewees are travelling and as a result, interviews may lose their natural flow and rhythm (Trier-Bieniek, 2012).

Glogowska et al., (2011) observes that in one interview the interviewee was commuting in a train from work to home. The telephone call would often abruptly end and the interviewer had to call again. As a solution prompts were used to remind the interviewer what was been discussed before the call disconnected (Glogowska et al., 2011).

Two observations from the authors' study are relevant here. First, most managers scheduled the interview at their place of work. Some managers booked a conference or visitor room, availing the teleconferencing facility, while others (often senior managers) would take the interview in their private office. There were three exceptions to this with one manager opting to take the interview while in her car (which was parked), another in a hotel while visiting another country, and one at home one evening.

Second, environmental noise was a factor during two interviews. One of these interviews was conducted on a face-to-face basis with the manager who suggested having the interview in a cafe over a cup of coffee. Whilst the relaxed environment of the cafe provided an excellent opportunity for building rapport, the background noise made transcription 
difficult. The other interview was by telephone in a noisy office environment. Although transcription was difficult, the interview/communication process itself was not affected as interviewer/interviewee could clearly hear each other during the interview. Therefore, while it is generally recommended that managers be allowed to choose the venue for the interview (Mealer and Jones, 2014), researchers should advise against a noisy venue.

\subsubsection{Interview material}

Stephens, (2007) observes that it was difficult to provide telephone interviewees with material that he provided to his face-to-face interviews. This material comprised of research papers written by the interviewees (university professors). However, Stephens (2007) also notes that as he grew in confidence during later interviews reduced the material he brought along to a notebook and pen. In accounting research, interviewers may want to refer to accounting records and other technical material. In the authors' study it quickly became clear that most documents can be emailed to or from interviewees before or during the interview. However, emailing voluminous preparatory material before the interview may put interviewees off by suggesting an onerous and time-consuming interview process.

In the study it was observed that during the interview, some managers would remark "let me just grab that file while we talk" or "let me just pull out that file from my laptop" or "looking at the reports on my shelf I would say". A telephone (or computer-based audio) interview allows the interviewee to consult confidential documents during the interview without the presence of the interviewer. The manager can then decide what information they are comfortable sharing. Thus, the interviewer observed that the interview guide, a notebook, a pen and perhaps a glass of water was all that was required.

\subsubsection{Scheduling of interviews}

Interviews (telephone or computer-based) should be scheduled at a date and time that is most convenient to the interviewee (Burke and Miller, 2001; Mealer and Jones, 2014). The drawback is that interviews may take place in the evenings or over the weekends and researchers may need to maintain a record if they wish to be reimbursed for telephone calls (Chapple, 1999). This presented less of a challenge in the authors' study, as most managers preferred to take the interview during office hours (section 4.2.7 above).

Researchers interviewing participants located elsewhere need to consider time differences (Kazmer and Xie, 2008). Furthermore, unexpected cancellations and requests for rescheduling are quite common in telephone (and computer-based) interviews (TrierBieniek, 2012; Cachia and Millward, 2011; Chapple, 1999). The observations from the authors' study suggest that both issues will occur when interviewing busy managers based in geographically dispersed locations. Thus researchers need to constantly check their emails and be ready to respond to requests for rescheduling immediately.

\subsubsection{Data organisation}

Burke and Miller (2001) recommend the allocation of codes to interview participants before conducting the interview. This facilitates subsequent analysis. In the authors' study an excel file was used to summarize the basic details of each interview i.e. date, start and end time, duration, names, comments, interview mode, location (if face-to-face), etc. This summary should be updated at the conclusion of each interview, as it facilitates organisation and the preparation of summary interviewee tables to be used in the method section of the research paper. 
The following steps should be undertaken during the interview itself:

\subsubsection{Use an introductory script}

Researchers may need to consider using an introductory script for participants that may not have read the invitation letter (Burke and Miller, 2001; Chapple, 1999). This script should provide a brief and positive introduction of the research project, how important their participation is to the research, an introduction of the interviewer, identify any sponsor, state that the interview will be recorded, data will be kept confidentiality, participant names will be kept anonymous, explain how the information will be used and the estimated duration of the interview (Burke and Miller, 2001). However, in the authors' study it was found that, given managers' busy schedules, the introductory script should be short and to the point.

\subsubsection{Adopt a conversational style}

Researchers should adopt a conversational style (Silverman, 2013) and the aim should be to have a great conversation (Hermanowicz, 2002). This involves a natural free flowing conversation as opposed to a superficial encounter. Interview questions should be read out in a conversational tone and the researcher should avoid awkward pauses (Burke and Miller (2001). This requires knowing your interview guide well.

The observations from the authors' study are that a conversational style works well when interviewing managers. The researcher attempted to sound friendly and relaxed but also to give the impression of a professional and serious academic researcher. During the interview researchers should not show surprise or disapproval with a person's responses. Finally, interviewers should be courteous and unbiased.

\subsubsection{Use the interview guide in a flexible manner}

A conversational style requires that the interview guide be used in a flexible manner (Silverman, 2013). Departures from the guide is inevitable and encouraged (Bryman, 2012 ). Researchers have the freedom to change the flow of questions and to field new questions in pursuit of new sub-topics that are identified during the conversation (Flick, et al., 2004).

Thus, the emphasis is on carefully listening to the interviewee and adjusting the interview guide according to the conversation as opposed to rigidly adhering to the guide. The researcher should remember that this is a conversation and should attempt to execute a natural free flowing conversation which is loosely guided by the interview guide (Hermanowicz, 2002).

\subsubsection{Communicating without visual cues}

\section{Listen carefully and articulate clearly}

Interviewers need to listen carefully to interviewees (Sturges and Hanrahan, 2004). This assists in assessing whether the interviewee has answered the question, as well as the interviewee's degree of involvement/interest in the interview, the need to probe further, the identification of new probing questions, and the refining/improvement of follow-up questions (Fontana and Frey, 2005; Trier-Bieniek, 2012).

Interviewers also need to listen to and pick up on changes in verbal cues such as pauses, hurried answers, tones etc. and indicate if interviewees are confused, hesitating, or experiencing frustration (Cachia and Millward, 2011; Carr and Worth, 2001; Chapple, 1999). 
This helps the interviewer to recognise signs of discomfort, frustration, anger, or confusion. As interviewers cannot use body language and facial expressions as a tool to probe answers every question should be clearly articulated to the interviewee (Holt, 2010; Stephens, 2007).

\section{Provide feedback and sound interested}

It pays to provide interviewees with feedback and sound interested. In some studies, participants frequently asked whether their answers were appropriate (Holt, 2010). However, even if they do not, interviewers should provide feedback to interviewees that provide open, honest and insightful answers by saying something like "this is the kind of information we want" (Burke and Miller, 2001). If interviewees are finding it difficult to answer the question or provide a vague answer the interviewer should try and rephrase the question (Holt, 2010). If interviewees are avoiding a closed ended question, ask them something like "in general, what would you say" (Burke and Miller, 2001).

Interviewers need to sound interested in the responses (Chapple, 1999; Glogowska, et al., 2011). In the authors' study, the interviewer would remark "interesting" and "this is a really helpful/good example". Finally, let the participant know if you cannot hear them.

\section{Communicate presence}

Interviewer silence can create the impression of interviewer absence, reservation and/or disapproval (Holt's, 2010). Interviewee feedback showed that interviewees would have liked greater participation in the interview by the researcher (Holt, 2010). The challenge for the researcher is to communicate their presence and approval, whilst not interrupting the interviewee (Stephens, 2007). Holt (2010) recommends carefully using umm's and ah's in the conversation. This is supported by Irvine et al., (2012) who find that acknowledgement tokens in the form of 'yeah', 'okay', 'right', given by the interviewer to the interviewee as an indication of being present and understanding what the interviewee was saying was found to be more frequent than face-to-face interviews.

We observed that while using acknowledgement tokens was necessary, care should be taken. Some participants are comfortable with 'yeah' and 'right' and they give the conversation a more natural flow. Other participants, although not uncomfortable with these, may misinterpret them as an interruption. These interviewees would either stop talking or quickly conclude on what they were saying in order to give the interviewer a chance to speak.

As a solution, the study recommends starting the interview conversation with a few short easy to answer questions (Hermanowicz, 2002). This gets the conversation going and both interviewer and interviewee get a chance to adjust to each other's communicational styles. The use of ' $u m m$ ' and 'ah' can be evaluated to assess the interviewees comfort and understanding of them.

Finally, pausing to clearly articulate questions can be misunderstood as a request to continue speaking. Stephens (2007) recommends that if you are pausing to develop a question ensure that you let your interviewer know this either explicitly or through the use of "ah" and "er". 


\section{Taking notes and writing probes}

Interviewers should remain silent while the interviewee is speaking to allow them sufficient time to complete their answers (Stephens, 2007). The interviewer should not hurry the interviewee and should ensure that the interviewee feels that their views and opinions have been noted and seen as valuable input (Glogowska et al., 2011). While the interviewee is answering, the interviewer can take notes and write probes without distracting interviewees (Chapple, 1999; Stephens, 2007). Once interviewees have completed their response, the interviewer should ask follow-up questions. Furthermore, maintaining notes also provides a form of backup in case of a recording malfunction (Burke and Miller, 2001).

In the authors' study the interviewer reduced reliance on note taking over the course of the interviews. Note taking was observed as a distraction, which caused the interviewer to focus more on writing rather than listening/understanding. Having said that, every interviewer has their own style and some may prefer note taking, as it helps improve focus and/or assists in identifying probes and prompts. Thus, the approach adopted will depend upon the interviewer's personal preferences.

\subsubsection{Start, middle and end}

The following approach was used to start off the interview:

- "Hello/hi! How are you?"

- "Let me put you on speaker and switch on my audio recorder".

- "Let me start off by saying, thank you again, for taking time out of your busy schedule to participate in this study".

- "We in the academic community rely on the support of the business community to learn and find out what's going on. Your participation is greatly appreciated".

- "So if you're ready can we start?"

This approach offers an effective way to break the ice and kick start the conversation. The researcher expresses gratitude to interviewees for taking time out from their busy schedules and highlights the importance of their participation. The approach combined formal and informal words (and tone of voice) to communicate in a polite and respectful manner the researcher interest in hearing what the interviewee has to say (Hermanowicz, 2002).

The first question asked was kept simple and easy to answer (Hermanowicz, 2002).

- "So if we can start off with a bit about yourself, your background and role in the organisation, and we'll take it from there?"

Using simple personal questions encourage interviewees to talk about themselves (e.g. where they live, where they had worked etc.) and is an effective technique in building rapport as well as gaining important background data (Cachia and Millward, 2011; Mealer and Jones, 2014).

Probe, rephrase and politely persist with your probes

Following on from this the conversation moved to the main topic of the research.

- "Can you walk me through the process you use in preparing a sustainability report? Take me through the various stages from the start till the end, including when you're engaging with the sustainability assurance providers?" 
Here the authors observed that while some interviewees provided a very detailed description of the entire process others would need to be probed in order to get more detailed information on each stage of the process. Consequently, researchers should use the initial stages of the interview to familiarize the interviewee with the depth of answers required through probes.

Following on from this researcher's next question was:

- "Having gone through the whole process/now that I have a really good understanding of the entire process what in your opinion is the impact of the sustainability assurance engagement on your organisation?"

The question was kept broad to allow the interviewee to explore their own perspectives on how the sustainability assurance engagement impacted their organisation. Furthermore, the sequencing of the questions is designed to ensure that this question/stage of the interview was only discussed after the interviewee had described their process.

This was a stage of the interview in which interviewees experienced more difficulties. Under such circumstances, the researcher should politely persistent (Hermanowicz, 2002). This requires using probes as well as rephrasing questions, often using different voice tones. Persistence is also a way of showing your interest.

For example:

- "What recommendations did your assurance providers give you?"

- "What recommendations did you implement?"

- "Which recommendations did you not implement?"

- "Why did you not implement those recommendations?"

- "Can you provide an example?" This was an especially effective probe and could be used often. Examples can help to illustrate the experiences of an interviewee without having to use visual cues. Examples are also very useful during the write-up stage of the research.

\section{Ending on a positive note}

The interview was concluded in the following manner:

- "Well I've run out of questions to ask (laugh). Is there anything else, any point that you feel is important, that I may have missed that you think should be included in the research?"

- "Thank you, this was really helpful! I've got some good points here!"

This allowed the interviewer to end the interview on a positive note with the interviewee (Hermanowicz, 2002). Additionally, questions designed to gain data on demographic variables should be fielded at the need of the interview so as not to influence the interviewee who may start to guess what questions will be asked (Burke and Miller, 2001).

In this way the interview conversation was organized into topics/stages with one topic leading to another (Hermanowicz, 2002). The individual questions were sequenced to take the interviewee from one topic into the next (Hermanowicz, 2002). 


\subsubsection{Seeking commonalities or the naive listener}

Some researchers have attempted to identify commonalities with their interviewees in an attempt to build a relationship and achieve rapport. For example, Chapple (1999) shared informed participants that she too had experienced similar medical problems and that she was a registered nurse. The aim was to share personal experiences in order to make participants more comfortable in opening up and sharing their personal experiences. Alternatively, other researchers recommend adopting the position of a 'naive' listener (Glogowska, et al., 2011). The interviewer is presented as neutral third party with no knowledge of the phenomenon under investigation.

In the authors' study interviewees knew that the interviewer was from an accounting background and had knowledge of accounting, reporting and auditing. However, the interviewer did not know how sustainability reports were prepared or how they were assured. Consequently, the interviewer adopted the position of a naive listener in respect of these matters. This encouraged the managers to discuss at length their experiences of and perspectives on sustainability reporting and sustainability assurance.

\subsubsection{Interviews cut short}

It was observed that in two interviews, the managers at the start of the interview stated that an urgent matter had come up and that they could not give the initially agreed time of 1 hour. Consequently, the interview was rescheduled to continue the next day. "Yeah if that's alright, l'd be happy to touch base tomorrow". Interviewers should make notes regarding what was covered and provide a brief introduction to the interviewee at the start of the second interview session. For example, "well yesterday we discussed $X$, so today if we could talk about $Y$ that would be great". However, the time between the first and the second session should not be too long. If this is unavoidable, the interviewer should spend more time summarizing what was discussed in the first interview in order to remind the interviewee of the territory covered in the first interview.

\subsubsection{Providing comfort to interviewees}

Researchers need to secure formal approval for their research from their university's ethics committee and make this known to interviewees (Glogowska, et al., 2011). Researchers can also encourage with phrases such as "it's okay, please take your time" or "we can reschedule if you like". This provides emotional support and conveys compassion and empathy when discussing sensitive issues (Trier-Bieniek, 2012). Researchers may also consider providing interviewees with the contact details of a professional counsellor both before (at the invitation stage) and at the conclusion of the interview (Glogowska, et al., 2011; Trier-Bieniek, 2012). In the authors' study this was not a problem and it is unlikely that such a challenge will occur when interviewing managers on how they undertake their role.

The following steps should be undertaken after conducting the interview:

\subsubsection{Immediately after the interview}

Researchers should complete any notes and field diaries accurately as soon as possible after the interview to help contextualise the interview (Glogowska, et al., 2011; Burke and Miller, 2001). In the authors' study, an excel file was updated with a summary of the interview and notes regarding any follow-up queries that needed to be made. For example, managers may have promised to send documents or introduce the authors to other potential participants. 
Interviewers are also encouraged to reflect on the conversation (Hermanowicz, 2002). The interviewer should recall key issues identified through the conversation and further areas to probe either in follow up questions (that were emailed and/or discussed over the telephone at a subsequent date) and/or to ask other participants in future interviews. The interviewer needs to reconsider the order of questions for future interviews. The interviewer should also identify better ways of asking questions including tone of voice, use of formal and informal language, and the pace of the interview.

The recording of the interview should be immediately saved onto a computer. The recording on the digital recorder and the smart phone should be immediately deleted as these can be lost or stolen. Backups of the digital audio files need to be maintained in case the computer crashes. The computer and/or files should be password protected (or encrypted) in order to ensure that the data remains confidential. Hard copies of files and documents should be stored in locked cabinets.

\subsubsection{Transcription, analysis and findings}

The researcher may want to share the findings with the participants (Glogowska, et al., 2011). Consequently, the contact details of participants should be maintained. Researchers need to set aside sufficient time for the subsequent transcription (Cachia and Millward, 2011) and data analysis (Burke and Miller, 2001). In the authors' study, time was allocated to scheduling appointments, conducting interviews, and transcribing interviews on a daily basis. A discussion of data analysis is beyond the scope of this study.

Table 2 provides a summary of the strategies described above to ensure useful telephonic (and computer-based) qualitative research interviews. 
Table 2: Strategies for using the telephone in qualitative research interviews

\begin{tabular}{|c|c|c|}
\hline & STRATEGY & DISCUSSION \\
\hline \multicolumn{3}{|c|}{ Before the interview } \\
\hline \multirow[t]{3}{*}{1} & \multirow[t]{3}{*}{ The interview guide } & A good interview guide helps in building rapport. \\
\hline & & Test the guide on a team member or colleague. \\
\hline & & After conducting a number of interviews review and revise the guide if necessary \\
\hline \multirow[t]{3}{*}{2} & \multirow{3}{*}{ Recruiting participants } & Tailor your recruitment approach \\
\hline & & Cold calling is effective if the research is not on a personally sensitive issue \\
\hline & & Maintain a call log \\
\hline \multirow[t]{3}{*}{3} & \multirow{3}{*}{$\begin{array}{l}\text { Pre-interview telephonic } \\
\text { conversation }\end{array}$} & Sell the research project and immediately address concerns \\
\hline & & Build rapport and create interest \\
\hline & & The interview style \\
\hline \multirow[t]{3}{*}{4} & \multirow[t]{3}{*}{ Email communication } & Provide all participants with an email invitation \\
\hline & & Email a participant information sheet and a consent form \\
\hline & & Maintain a record of email communication with participants for later use \\
\hline \multirow[t]{2}{*}{5} & \multirow[t]{2}{*}{ Negotiating interview time } & Negotiate with interviewees for more time \\
\hline & & Be flexible and offer to conduct the interview when the participant is free \\
\hline \multirow[t]{2}{*}{6} & \multirow[t]{2}{*}{ Setting up the equipment } & Telephone interviews \\
\hline & & Computer-based interviews \\
\hline \multirow[t]{4}{*}{7} & \multirow{4}{*}{$\begin{array}{l}\text { The interview location and } \\
\text { environment }\end{array}$} & Let interviewees select their preferred environment \\
\hline & & Make sure you are comfortable, the room is quiet and free from interruption \\
\hline & & Make sure that the interviewee is ready to proceed or offer to reschedule to another date \\
\hline & & $\begin{array}{l}\text { Be ready for disruptions and dropped calls when interviewing participants who are commuting from } \\
\text { work to home during the interview }\end{array}$ \\
\hline \multirow[t]{2}{*}{8} & \multirow[t]{2}{*}{ Interview material } & $\begin{array}{l}\text { Avoid emailing too much material before the interview as this makes the interview appear more time } \\
\text { consuming and could scare off participants. }\end{array}$ \\
\hline & & $\begin{array}{l}\text { Communicate a broad outline of the interview questions/topics and allow the participant to prepare } \\
\text { accordingly }\end{array}$ \\
\hline \multirow[t]{3}{*}{9} & \multirow[t]{3}{*}{ Scheduling of interviews } & Allow participants to set a date and time that they prefer \\
\hline & & Consider international time differences \\
\hline & & Be ready to organize your schedule to suit that of your participants \\
\hline \multirow[t]{2}{*}{10} & \multirow[t]{2}{*}{ Data organisation } & Allocate a code number to the interview \\
\hline & & Prepare an excel file to summarize the details of each interview \\
\hline During $\mathrm{t}$ & rview & \\
\hline 1 & Use an introductory script & Consider using an introductory script at the start of the interview \\
\hline 2 & Adopt a conversational style & Read questions in a conversational tone \\
\hline & & Be friendly yet professional \\
\hline & & Be respectful, courteous, and unbiased \\
\hline 3 & $\begin{array}{l}\text { Use the interview guide in a } \\
\text { flexible manner }\end{array}$ & The interview guide is to be used in a loose flexible manner \\
\hline 4 & Communicating without visual & Listen carefully \\
\hline & cues & Articulate questions clearly \\
\hline & & Provide feedback and sound interested \\
\hline & & Communicating presence \\
\hline & & Take notes but remember to focus on listening \\
\hline 5 & Start, middle and end & Probe, rephrase and politely persist with your probes \\
\hline & & End on a positive note \\
\hline 6 & $\begin{array}{l}\text { Seeking commonalities or the } \\
\text { naive listener }\end{array}$ & $\begin{array}{l}\text { Some interviewers prefer to highlight commonalities and share their own personal experiences in } \\
\text { order to build rapport }\end{array}$ \\
\hline & & Others prefer to present themselves as a naive listener \\
\hline 7 & Interviews cut short & Phone back \\
\hline 8 & Providing comfort to & Follow university guidelines and seek ethical approval for the research \\
\hline & interviewees & Provide comfort to interviewees and convey compassion and empathy \\
\hline & & Provide the contact details of counsellors before and after the interview \\
\hline After the & iew & \\
\hline 1 & Immediately after the interview & $\begin{array}{l}\text { Save the audio recording, delete the recording from the recorder and prepare a backup stored safely } \\
\text { or password protected or encrypted }\end{array}$ \\
\hline & & Review and complete your interview notes \\
\hline & & $\begin{array}{l}\text { Reflect on the interview to assess how it can be improved. This relates to both the interview guide } \\
\text { and to the interview conversation }\end{array}$ \\
\hline 2 & Transcription, & Share the research findings with participants \\
\hline & findings & Allocate sufficient time \\
\hline
\end{tabular}




\section{$5 \quad$ Summary and conclusion}

The aims of this study are to: (1) review the literature examining the arguments for and against the telephonic qualitative research interview, (2) to develop criteria for assessing when the use of the telephone is suitable in qualitative research, and if suitable (3) to offer detailed strategies for the effective use of this data collection instrument. The study leverages the experience of the authors with an accounting research project involving the use of telephone, computer-based audio and face-to-face interviews. The insights gained from this project were synthesised with the existing literature to address the three research objectives identified above.

The literature review highlights that the arguments of traditionalists against the use of the telephone in qualitative research and weighs these up against those of researchers who have tested and compared the telephone against the face-to-face interview method. While the arguments of the critics carry some weight, it is also necessary to consider that researchers who had used the telephone said that there is "no real difference whatsoever" in the quality of their data when they used the telephone compared to face-to-face interviewing (Tucker and Parker, 2014, pp. 25) and that "for the most part, the paper would have been largely the same" (Tucker and Parker, 2014, pp. 26). Thus, in some cases decisions relating to interview mode (telephone or face-to-face) are not always made on a rational basis. The telephonic qualitative research interviews actually have many advantages, such as being more cost effective, less time consuming, and seen as less intrusive, thereby potentially increasing the likelihood of participation.

Second, the study identifies key criteria which resarchers should consider before using the telephonic qualitative research interview. This includes evaluting the need for contextual data to understand the phenomena being investigated. This is particularly important for ethnographic research as well as other qualitative studies. The researcher may need to supplement the telephonic qualitative research interview with observations (i.e. a second data collection instrument). Whether this is sufficient is a matter of judgement for the researchers. Additionally, researchers should evaluate their target population and their experience and level of comfort with using the telephone (or computer-based technologies such as Skype) for communication purposes. Researchers also need to evaluate their own experience and confidence with using telephone (or computer-based technologies) in communicating with friends, families, and work colleagues. A computer-based video interview using Skype (as opposed to a Skype audio only interview) represents an excellent alternative to the telephonic qualitative interview, provided that interviewees indicate that they are comfortable using it and any technical issues can be dealt with satisfactorily. The severity of these technical issues related to internet-based video interviewing are expected to reduce as the technology improves. Finally, time and cost savings alone should not be the justification for using the telephone (and computer-based) interviews and researchers should ensure they have also addressed the other four criteria.

If these criteria are met this study offers a comprehensive set of strategies based on the authors' experience of, and reflections on, an accounting research project involving managers' work, as well as on the prior literature (that mostly dealt with different interviewee groups and focussed on these interviewees' personal/emotive experiences). The step-by-step guide is summarised in Table 2. 
The guidance covers activities before, during, and after the interview. Before the interview, researchers strive to develop a well thought out interview guide, tailor their approach to recruiting participants, carry out a pre-interview telephonic conversation with participants, send all participants an email invitation, negotiate interview time, set up and test the equipment, allow participants to select their preferred environment, consider material to have during the interview, schedule interviews at a date and time that suits interviewees, and prepare an excel sheet to summarize the important details of each interview.

During the interview, researchers may consider starting off with an introductory script, adopting a conversational style, using the interview guide in a flexible manner, listening carefully and articulating clearly, providing feedback and sounding interested, taking notes and probing politely, structuring the interview so that it follows a natural progression from start to end, consider building a relationship with participants based on commonalities or adopting the position of a naive listener, be ready for interviews that might be cut short, and providing verbal comfort to interviewees should the need arise.

After the interview, researchers should save their audio recording onto a computer and prepare a backup, delete the recording on the audio recorder, update the excel interview file, complete their interview notes, re-read their interview notes, reflect on the interview to evaluate both the questions asked and the quality of the conversation, and allocate sufficient time for transcription and analysis.

In conclusion, the telephone provides qualitative researchers, especially those undertaking accounting and management research with a sound data collection instrument. However, researchers should consider the objectives of their research and the nature of the data they require to address their research question. If the study does not require contextual data (or if this can be collected using an additional data collection instrument); if the study participants are experienced and comfortable using the telephone in communication; and finally if the researcher has experience using this mode of interviewing then the qualitative telephone interview will issues related to the time and cost involved in travelling to many different business sites can be prohibitive, that other work commitments may preclude multiple trips to conduct interviews, and that international travel can be costly and complicated. Therefore, the telephonic qualitative research interview can be a valuable qualitative data collection instrument. 


\section{References}

Braun, V. and Clarke, V. (2013), Successful Qualitative Research, Sage Publications Ltd, London. Bryman, A. (2001), Social Research Methods, Oxford University Press, Oxford.

Bryman, A., 2012 . Social Research Methods (4th ed.). Oxford University Press, Oxford.

Burke, L. A. and Miller, M. K. (2001), "Phone Interviewing as a Means of Data Collection: Lessons Learned and Practical Recommendations", Forum: Qualitative Social Research, Vol. 2 No. 2.

Cachia, M. and Millward, L. (2011), "The telephone medium and semi-structured interviews: a complementary fit", Qualitative Research in Organizations and Management: An International Journal, Vol. 6 No. 3, pp. 265-277.

Carr, E. C. and Worth, A. (2001), "The use of the telephone interview for research", Nursing Times Research, Vol. 6 No. 1, pp. 511-524.

Chapple, A. (1999), "The use of telephone interviewing for qualitative research", Nurse Researcher, Vol. 6 No. 3, pp. 85-93.

Deakin, H. and Wakefield, K. (2014), "Skype interviewing: reflections of two PhD researchers", Qualitative research, Vol. 14 No. 5, pp. 603-616.

Flick, U., von Kardorff, E. and Steinke, I. (2004), A Companion to Qualitative Research, Sage Publications Ltd, London.

Fontana, A. and Frey, J. (2005), "The interview: From neutral stance to political involvement". In, The Sage handbook of qualitative research (3rd ed.), Sage Publications Ltd, Thousand Oaks, CA, pp. 695-727.

Frey, J. H. (1983), Survey research by telehone, Sage Publications Ltd, Thousand Oaks, CA

Gillham, B. (2005), Research Interviewing: The Range of Techniques, McGraw-Hill Education, Berkshire.

Glogowska, M., Young, P. and Lockyer, L. (2011), “Propriety, process and purpose: considerations of the use of the telephone interview method in an educational research study", Higher Education, Vol. 62 No. 1, pp. 17-26.

Hanna, P. (2012), "Using internet technologies (such as Skype) as a research medium: a research note", Qualitative Research, Vol. 12 No. 2, pp. 293-242.

Hermanowicz, J. C. (2002), "The great interview: 25 strategies for studying people in bed", Qualitative Sociology, Vol. 25 No. 4, pp. 479-499.

Holt, A. (2010), "Using the telephone for narrative interviewing: a research note", Qualitative Research, Vol. 10 No. 1, pp. 113-121.

Irvine, A., Drew, P. and Sainsbury, R. (2012), "'Am I not answering your questions properly?' Clarification, adequacy and responsiveness in semi structured telephone and face to face interviews", Qualitative Research, Vol. 13 No. 1, pp. 87-106.

Irvine, H. and Gaffikin, M. (2006), "Getting in, getting on and getting out: reflections on a qualitative research project", Accounting, Auditing \& Accountability Journal, Vol. 19 No. 1, pp. 115-145.

Kazmer, M. M. and Xie, B. (2008), "Qualitative interviewing in internet studies: Playing with the media, playing with the method", Information, Communication \& Society, Vol. 11 No. 2, pp. 257-278.

Kvale, S. and Brinkmann, S. (2008), InterViews: Learning the craft of qualitative research interviewing (2nd ed.), Sage Publications, Thousand Oaks, CA.

Mealer, M. and Jones, J. (2014), "Methodological and ethical issues related to qualitative telephone interviews on sensitive topics", Nurse Researcher, Vol. 21 No. 4, pp. 32-37.

Miles, M. B., Huberman, A. M. and Saldana, J. (2014), Qualitative Data Analysis: A Methods Sourcebook (3rd ed.), Sage Publications Ltd, Thousand Oaks, CA.

Nassar, M., Al-Khadash, H. A. and Sangster, A. (2011), "The diffusion of activity-based costing in Jordanian industrial companies", Qualitative Research in Accounting and Management, Vol. 8 No. 2, pp. $180-2000$.

Novick, G. (2008), "Is there a bias against telephone interviews in qualitative research?", Research in Nurshing \& Health, Vol. 31 No. 4, pp. 391-398. 
Opdenakker, R. (2006), "Advantages and Disadvantages of Four Interview Techniques in Qualitative Research", Forum: Qualitative Social Research, Vol. 7 No. 4.

Patton, M. Q. (2002), Qualitative Research \& Evaluation Methods (3rd ed.), Sage Publications Ltd, London.

Pew Research Centre (2015), "1. Communications Technology in Emerging and Developing Nations", available at: http://www.pewglobal.org/2015/03/19/1-communications-technology-inemerging-and-developing-nations/, (Accessed 8 August 2015).

Qu, S. Q. and Dumay, J. (2011), "The Qualitative Research Interview. Qualitative Research in Accounting \& Management", Vol. 8 No. 3, pp. 238-264.

Rowley, J. (2012), "Conducting research interviews", Management Research Review, Vol. 35 No. 3/4, pp. 260-271.

Seitz, S. (2015), "Pixilated partnerships, overcoming obstacles in qualitative interviews via Skype: a research note", Qualitative Research, Vol. 15 No. 2, pp. 1-7.

Shuy, R. W. (2003), "In person versus telephone interviewing", In: Inside Interviewing: New Lenses, New Concerns, Sage Publications Ltd, Thousand Oaks, CA, p. 175-193.

Silverman, D. (2013), Doing Qualitative Research, Sage Publications Ltd, London.

Stephens, N., (2007), "Collecting Data from Elites and Ultra Elites: Telephone and Face-to-Face Interviews with Macroeconomists", Qualitative Research, Vol. 7 No. 2, pp. 203-216.

Sturges, J. E. and Hanrahan, K. J. (2004), "Comparing telephone and face-to-face qualitative interviewing: a research note", Qualitative Research, Vol. 4 No. 1, pp. 107-118.

Sweet, L. (2002), "Telephone interviewing: Is it compatible with interpretive phenomenological research?", Contemporary Nurse, Vol. 12 No. 1, p. 58-63.

Tesch, R. (1990), Qualiatative Research: Analysis Types and Software Tools, Psychology Press, London.

Trier-Bieniek, A. (2012), "Framing the telephone interview as a participant-centred tool for qualitative research: a methodological discussion", Qualitative Research, Vol. 12 No. 6, pp. 630-644.

Tucker, B. P. and Parker, L. D. (2014), "Comparing interview interaction modes in management accounting research: A case to answer?", paper presented at AAA 2015 Management Accounting Section (MAS) Meeting, available at: http://papers.ssrn.com/sol3/papers.cfm?abstract id=2480247, (accessed 5 August 2015).

Vogl, S. (2013), "Telephone Versus Face-to-Face Interviews: Mode Effect on Semi-Structured Interviews with Children", Sociological Methodology, Vol. 43 No. 1, pp. 133-177. 